\title{
Correction to: High-throughput profiling of microbial community structures in an ANAMMOX-UASB reactor treating high-strength wastewater
}

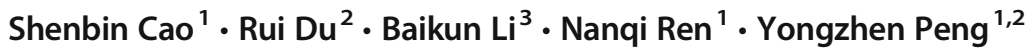 \\ Published online: 19 February 2020 \\ (C) Springer-Verlag GmbH Germany, part of Springer Nature 2020
}

Correction to: Appl Microbiol Biotechnol (2016) 100:6457-6467 https://doi.org/10.1007/s00253-016-7427-6

The published online version contains mistake in the affiliation ID of the author Baikun Li. The correct presentation is given above.

Publisher's note Springer Nature remains neutral with regard to jurisdictional claims in published maps and institutional affiliations.

The online version of the original article can be found at https://oi.org/ 10.1007/s00253-016-7427-6

\section{Yongzhen Peng}

pyz@bjut.edu.cn

1 State Key Laboratory of Urban Water Resource and Environment, Harbin Institute of Technology, Harbin 150090, China

2 Key Laboratory of Beijing for Water Quality Science and Water Environment Recovory Engineering, Engineering Research Center of Beijing, Beijing University of Technology, Beijing 100124, China

3 Department of Civil and Environmental Engineering, University of Connecticut, Storrs, CT 06269, USA 